\title{
Visitations by Snowshoe Hares (Lepus americanus) to and Possible Geophagy of Materials from an Iron-Rich Excavation in North-Central British Columbia
}

\author{
Roy V. ReA ${ }^{1}$, Christina L. StumpF ${ }^{1}$, and DeXter P. Hodder ${ }^{2}$ \\ ${ }^{1}$ University of Northern British Columbia, 3333 University Way, Prince George, British Columbia V2N 4Z9 Canada \\ ${ }^{2}$ John Prince Research Forest, P.O. Box 2378, Fort St. James, British Columbia V0J 1P0 Canada
}
Rea, Roy V., Christina L. Stumpf, and Dexter P. Hodder. 2013. Visitations by Snowshoe Hares (Lepus americanus) to and possi- ble geophagy of materials from an iron-rich excavation in north-central British Columbia. Canadian Field-Naturalist 127(1): 26-30.

Fecal pellet samples and photo data were collected and analyzed to investigate the suspected occurrence of geophagy of soils by Snowshoe Hares (Lepus americanus) at a small iron-rich mineral excavation in north-central British Columbia. Pellet samples from Snowshoe Hares collected near the excavation site in both February 2004 and 2005 showed higher levels of iron (II) sulphate in pellets than in samples from control areas $(P<0.05)$. Using remote wildlife camera technology, we determined that Snowshoe Hares accounted for $72 \%$ of visits by mammals to the site. Ninety percent of these visits occurred at night; this timing corresponds with the use of mineral licks by several other species of mammals in North America. Use occurred in winter (49\%) and spring (47\%), but was rare in summer and autumn, and may have coincided with periods of nutritional stress in Snowshoe Hares.

Key Words: excavation, fecal pellet, geophagy, iron, Snowshoe Hare, Lepus americanus, soil, wildlife camera, John Prince Research Forest, British Columbia.

The deliberate consumption of soil by animals (geophagy) has been documented in many species, including humans and other primates, ungulates, and birds (Krishnamani and Mahaney 2000; Maheney et al. 2000). Several hypotheses have been put forward to provide explanations for this behaviour, all relating to either gastrointestinal disorders or mineral deficiencies (Krishnamani and Mahaney 2000). Consumption of certain clay-rich soils allows relief from diarrhea and acts as a buffer against elevated levels of stomach acids (Dominy et al. 2004). Soil consumption also frequently occurs in order to neutralize plant secondary compounds, such as tannins (Faber et al. 1993; Houston et al. 2001). The minerals most commonly found in consumed soils include sodium, calcium, magnesium, potassium, iron, and aluminum (Wilson 2003).

There is little information in the literature pertaining to the nutritional requirements of hares (Lepus spp.); although geophagy has been documented in this genus, it is usually in relation to dietary sodium needs. Faber et al. (1993) reported on the utilization of salt blocks by Mountain Hares (Lepus timidus) in Sweden and suggested that increased use corresponded to increased nutritional stress associated with reproduction and seasonal dietary excesses of potassium. Incidents of soil consumption for the purposes of obtaining iron are uncertain; although Arthur and Gates (1988) reported that Black-tailed Jackrabbits (Lepus californicus) obtained dietary iron from soil, the study did not conclude that this was the likely purpose of soil consumption. Krishnamani and Mahaney (2000) noted, however, that most soils eaten by primates are reddish in colour and contain iron oxide.
The dietary iron requirements for rabbits and hares (Leporidae) are largely unknown. Iron is nonetheless an important mineral and plays several physiological roles in mammals, including oxygen transport. New Zealand White (domestic Oryctolagus cuniculus) does given supplemental iron sulphate responded to treatments with increases in maternal weight and litter size at birth and weaning; reduced mortality at birth and weaning; and increases in kit weight at weaning, milk yield, and levels of maternal plasma progesterone and estradiol-17ß (El-Masry and Nasr 1996). These findings suggest an overall increase in reproductive performance with iron supplementation.

The purpose of this study was to investigate, through the analysis of soils, fecal pellet samples, and wildlife camera data, the suspected occurrence of geophagy by Snowshoe Hares (Lepus americanus) at an iron-rich mineral excavation in north-central British Columbia that we discovered in the spring of 2001.

\section{Methods}

\section{Site characteristics}

The site is located on the northwest-facing bank of a mineral lick in the John Prince Research Forest $\left(54^{\circ} 35^{\prime} \mathrm{N}, 124^{\circ} 35^{\prime} \mathrm{W}\right), 50 \mathrm{~km}$ northwest of Fort St. James, British Columbia. The cavity appears to be natural, having been partially excavated by animals through to mineral soils, but not into parent materials. The excavation was not made by people. The site is located in a spruce-pine (Picea-Pinus) stand $\sim 120$ years old in the Dry Warm Sub-Boreal Spruce biogeoclimatic subzone (SBSdw) (Meidinger et al. 1991) at an altitude of $791 \mathrm{~m}$ above sea level. Soils in the area 
are composed primarily of orthic gray luvisols, which are neutral to slightly alkaline. The excavation was located beneath the root structure of a 35-year-old hybrid White Spruce (Picea glauca $\times$ engelmannii) tree, and the dimensions of the cavity, as measured in the spring of 2003, were $22 \mathrm{~cm}$ deep by $30 \mathrm{~cm}$ wide by $16 \mathrm{~cm}$ high.

Using microscopy, we sorted soils and measured particle sizes to the nearest micrometer on a homogenized subsample of $13.98 \mathrm{~g}$ of a handful of the material we collected in the spring of 2003. We also used microscopic hair analysis of samples of hairs that we collected from the rim of the excavation opening in an attempt to determine species moving in and out of the excavation.

\section{Data collection and analysis}

Photo data were collected from the late summer of 2003 through February 2005 using a TrailMaster TM1550 infrared trail monitor. The camera was mounted in a tree approximately $5 \mathrm{~m}$ from the mouth of the excavation and $1.5 \mathrm{~m}$ above the ground. Because the date and time imprinter on the camera was not functioning, photos were classified as either night or day based on the light conditions in the background of the photo. Season was assessed using date of film collection and the progression of plant phenology in the photos: mid-November through early March was classified as winter; mid-March to the end of May was classified as spring; and June through mid-November was classified as summer and autumn combined due to the small number of photographs taken during that period.

Fecal pellets were collected in February of 2004 and 2005 from three different sampling areas: those collected within a $20-\mathrm{m}$ radius of the excavation were classified as "excavation" site; pellets collected from $1-2 \mathrm{~km}$ from the excavation were classified as "control near," and samples collected farther than $2 \mathrm{~km}$ away (range 2-156 km) were classified as "control far."

Pellets were dried for 7 days at $20^{\circ} \mathrm{C}$ under a fume hood to a constant weight, then ground with a mortar and pestle, and analyzed for mineral content along with samples from the soil itself using an inductively coupled plasma (ICP) analyser.

Because there was extensive evidence of Snowshoe Hare browse on current annual shoots of Prickly Rose (Rosa acicularis) in the study area, we collected current annual shoots of this plant ( $\sim 20$ individual plant specimens) in February of 2004 and dried and ground them for ICP analysis. Samples were taken only from the control near sites because there was no evidence of browsing on any plant species at the excavation site itself.

Iron (II) sulphate concentration differences in feces were compared among sample areas using a two-factor analysis of variance with year and distance category as main and interaction effects. A Tukey's honestly significant difference (HSD) test was used for post-hoc comparisons (Gotelli and Ellison 2004). We specified an alpha level of $P<0.05$. All analyses were conducted using Statistica 9.0 (Statsoft 2009).

\section{Results}

Using Adorjan and Kolenosky (1969), we identified hair samples collected from the opening of the excavation as those of Snowshoe Hare. We classified all aggregate materials from the excavation as subangular blocky (Expert Committee on Soil Survey 1983) and determined that the soil was composed of several elements, but contained $86 \%$ iron. Soil particle sizes ranged from a fine powder to up to $2.5 \mathrm{~cm}$ in diameter with a mean particle size of $1.227 \mathrm{~mm}$ (SD 4.206).

Of 348 photographs recorded between late summer 2003 and February 2005, 130 contained images of animals. Of these, Snowshoe Hares were the most often photographed (Figure 1, Table 1). Table 1 details the occurrence of mammals at the site of the excavation. Two Canada Lynx (Lynx canadensis) were observed in the winter of 2003, and a pair of Snowshoe Hares was observed in April of 2004.

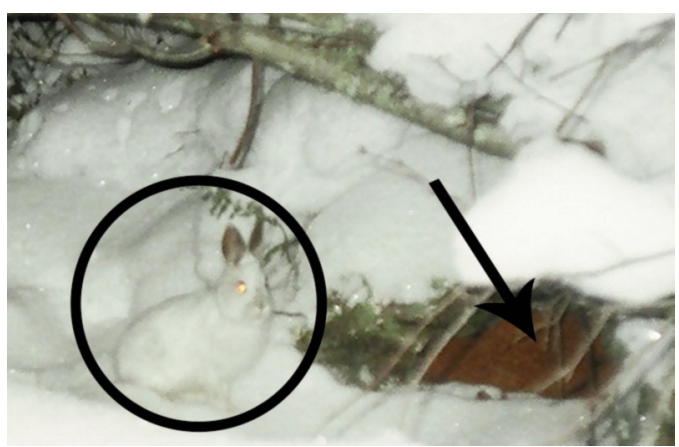

FIGURE 1. Snowshoe Hare (Lepus americanus) (circled) photographed at a mineral lick in the John Prince Research Forest, northwest of Fort St. James, British Columbia. The camera was set to take photographs of animals entering and exiting the iron-rich mineral excavation (arrow) over a 1.5-year period (Winter 2004).

Analysis of fecal samples indicated levels of iron (II) sulphate were higher in samples from the excavation site than from the controls in both 2004 and $2005\left(\mathrm{~F}_{1,2}=7.795 ; P=0.003\right.$; Figure 2). There were no differences between years $\left(\mathrm{F}_{1,2}=1.617 ; P=0.216\right)$ and there was no interaction between area and year $\left(\mathrm{F}_{1,2}=0.932 ; P=0.408 ;\right)$. Tukey's post-hoc comparisons indicated that differences existed specifically between Control Far 2004 samples and Excavation 2005 samples $(P=0.012)$ and between Control Far 2005 and Excavation 2005 samples $(P=0.013)$. The levels of iron in Prickly Rose samples were not higher than the levels of iron that we found in feces, and levels in Prickly Rose were similar in all collection locations. 
TABLE 1. Number of photographs recorded $(n)$ by species and season; time of day is the percentage of total pictures of that species in the particular season. Number is beam breaks resulting in photographs, and does not necessarily represent independent occurrences. Photographs taken in summer and autumn are combined due to small numbers recorded. In some instances, photographs were triggered by weather events and therefore did not contain photographs of animals.

\begin{tabular}{|c|c|c|c|c|c|c|c|c|}
\hline \multirow[b]{2}{*}{ Species } & \multirow[b]{2}{*}{$\begin{array}{l}\text { Photos } \\
(n=130)\end{array}$} & \multicolumn{2}{|c|}{ Winter } & \multicolumn{2}{|c|}{ Spring } & \multicolumn{2}{|c|}{ Summer and Autumn } & \multirow[b]{2}{*}{$\begin{array}{c}\text { Annual } \\
\text { total }\end{array}$} \\
\hline & & $\begin{array}{l}\text { Day } \\
(\%)\end{array}$ & $\begin{array}{l}\text { Night } \\
(\%)\end{array}$ & $\begin{array}{l}\text { Day } \\
(\%)\end{array}$ & $\begin{array}{l}\text { Night } \\
(\%)\end{array}$ & $\begin{array}{l}\text { Day } \\
(\%)\end{array}$ & $\begin{array}{l}\text { Night } \\
(\%)\end{array}$ & \\
\hline $\begin{array}{l}\text { Snowshoe Hare } \\
\text { (Lepus americanus) }\end{array}$ & 94 & 4.5 & 44.5 & 4 & 43 & 2 & 2 & 100 \\
\hline $\begin{array}{l}\text { Red Squirrel } \\
\text { (Tamiasciurus hudsonicus) }\end{array}$ & 17 & 23.5 & - & 76.5 & - & - & - & 100 \\
\hline $\begin{array}{l}\text { Moose } \\
\text { (Alces alces) } \\
\text { Deer }\end{array}$ & 10 & - & 70 & - & 30 & - & - & 100 \\
\hline $\begin{array}{l}\text { (Odocoileus spp.) } \\
\text { Canada Lynx }\end{array}$ & 7 & - & - & 85.7 & 14.3 & - & - & 100 \\
\hline (Lynx canadensis) & 2 & - & 100 & - & - & - & - & 100 \\
\hline
\end{tabular}

\section{Discussion}

Camera trap data from our study site indicate that Snowshoe Hares were the most common species using the excavation and that their activity was predominantly nocturnal, with $90 \%$ of visits occurring at night. Mineral consumption by other animals at mineral licks also tends to be a night-time activity (Fraser and Reardon 1980; Tankersley and Gasaway 1983; Couturier and Barrette 1988; Voigt et al. 2007). We found no evidence that this area was being used as a daybed or nursery or for cover by Snowshoe Hares or other animals. Rather, materials in the excavation appeared to be continually disturbed rather than matted or compacted with use.

Peak activity was recorded during winter and spring. This time frame corresponds to periods when Snowshoe Hares have reduced access to high-quality forage and may be under increased nutritional stress (Hodges et al. 2006). Murray et al. (1998) speculated that in years of peak Snowshoe Hare population numbers, nutritional stress can be exacerbated by increased intestinal parasite loads. Because iron supplementation can significantly reduce parasite loads (Olsen et al. 2000), increased iron consumption through geophagy may help to improve body condition during periods of nutritional and reproductive stress that coincide with winter and spring.

The photograph of a pair of Snowshoe Hares at the excavation site in spring 2004 suggests that the time period of use may correspond to reproductive events. The breeding season for Snowshoe Hares may extend up to seven months (March-September) across their geographical range and is strongly associated with photoperiod (Murray 2003). The onset of ovulation in Snowshoe Hares appears to be affected by environmental and ecological factors. For example, Vaughn and Keith (1981) demonstrated that overwinter body mass loss in female Snowshoe Hares is correlated with delays in the onset of conception in spring. This implies that the nutritional fitness of females affects breeding readiness (Murray 2003). El-Masry and Nasr (1996) report improved reproductive performance for rabbits fed supplemental iron in all parameters measured, and these findings may hint at why Snowshoe Hares target these soils. Images of other mammals from our cameras indicate that the excavation may also be of benefit to others.

Snowshoe Hares in the northern boreal forest normally eat willow (Salix spp.), birch (Betula spp.), soapberry (Shepherdia spp.), and White Spruce (Picea glauca) branchlets (Hodges and Sinclair 2003); however, in the study area, most evidence of browse was on Prickly Rose, despite the fact that those species mentioned above appear to be in good supply. We did not detect elevated iron levels in Prickly Rose and therefore do not ascribe the increased iron levels in fecal pellets to this source.

Mahaney et al. (1997) found that $0.15-0.20 \%$ of iron in soils consumed by chimpanzees could be extracted with an acid of the same $\mathrm{pH}$ as that of the digestive tract, making it a bioavailable iron. Iron in soils could therefore be an important nutritional source for Snowshoe Hares. Black-tailed Jackrabbits in Idaho were reported to have obtained $75 \%$ of the iron in their diet from soil consumption (Arthur and Gates 1988). We therefore suggest that increased iron levels in fecal pellets we sampled may be due to consumption of ironrich aggregate by Snowshoe Hares at the excavation site.

The mean home range size for Snowshoe Hares is $\sim 12.8$ ha, with core use areas $(50 \%)$ of 1.4 ha (de Bellefeuille et al. 2001). A significant difference between the fecal iron levels in the pellets from the excavation site and the pellets from the control far sites indicates that only the Snowshoe Hare pellets collected from within an approximate home range distance from the aggregate showed increased iron levels. This may be attributable to differences in iron levels of plants and/ or soils that Snowshoe Hares were consuming within these different home ranges, but was beyond the scope of this study to investigate in any detail. If geophagy 


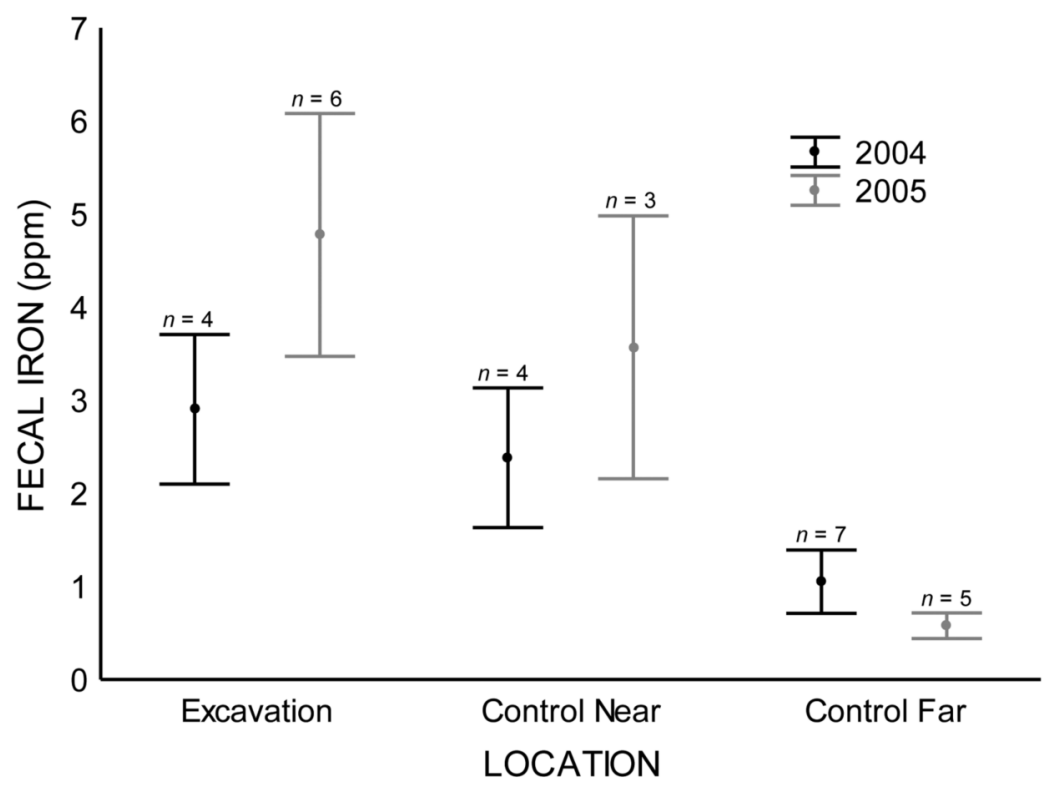

FIGURE 2. Mean ( \pm 1 S.E.) iron (II) sulphate concentrations in Snowshoe Hare (Lepus americanus) fecal pellet samples collected in February 2004 (black bars) and February 2005 (grey bars) at the mineral excavation site in the John Prince Research Forest, northwest of Fort St. James, British Columbia; near the excavation site (between 1 and $2 \mathrm{~km}$ away); and far $(2+\mathrm{km})$ from the excavation site.

was not occurring, it might be expected that fecal iron levels would have been similar throughout the study area, but of course that would depend on several factors (e.g., rock provinces, soil types) that were not examined.

Because the preferred habitat of Snowshoe Hares is mid-seral stage forests (10-25 years) (Potvin et al. 2005) and the excavation exists in an old-growth forest $\sim 300 \mathrm{~m}$ from younger forest stands, it appears that Snowshoe Hares were visiting the location to gain access to the iron-rich soil. Documentation of Canada Lynx at the excavation indicates that there is a potential risk of predation for the Snowshoe Hares that use the site. The fact that the Snowshoe Hares use the site regularly suggests that the site must be relatively important.

At less than $1300 \mathrm{~m}$ above sea level, the altitude in the John Prince Research Forest is not considered extreme. Animals at high altitude ( $>2500 \mathrm{~m})$ may have an increased need for iron to replenish hemoglobin due to increased oxygen demand (Mahaney et al. 1997), but that does not provide a plausible explanation for soil ingestion in this location.

Iron-mineral hunger primarily appears to be a tropical-subtropical phenomenon (Mahaney and Krishnamani 2003), but according to our research it may also occur in north-central British Columbia. Future research will be needed to ascertain more clearly whether the mineral aggregate is being eaten by Snowshoe
Hares. This could be partly accomplished by using newer video camera recording technologies. A less observational approach through destructive sampling of Snowshoe Hares and stomach content analysis could also be performed. Labeling the iron aggregate with a marker or dye that could be definitively identified in fecal pellets might prove useful. Blood samples could be taken from Snowshoe Hares near the excavation site and analyzed for serum iron levels and then compared to levels from Snowshoe Hares in control locations to determine if mineral absorption is occurring from soil ingestion. The mineral and nutritional composition of the complete local Snowshoe Hare diet, including levels of secondary plant compounds, should be determined while also considering the current phase of the population cycle and parasite loads in the area.

\section{Acknowledgements}

We would like to thank D. Dick and W. Hines for their assistance with the ICP analysis and B. LaValley and L. Sapergia for assistance in the field. We thank the John Prince Research Forest for funding the research and two anonymous reviewers for their comments on an earlier draft of this paper.

\section{Literature Cited}

Adorjan, A.S., and G.B. Kolenosky. 1969. A manual for the identification of hairs of selected Ontario mammals. Research Branch, Department of Lands and Forests. Research Report (Wildlife) No. 90. 64 pages. 
Arthur, W. J., and R. J. Gates. 1988. Trace element intake via soil ingestion in pronghorns and in black-tailed jackrabbits. Journal of Range Management 41: 162-166.

de Bellefeuille, S., L. Bélanger, J. Huot, and A. Cimon. 2001. Clear-cutting and regeneration practices in Quebec boreal balsam fir forest: effects on snowshoe hare. Canadian Journal of Forest Research 31: 41-51.

Couturier, S., and C. Barrette. 1988. The behaviour of moose at natural mineral springs in Quebec. Canadian Journal of Zoology 66: 522-528.

Dominy, N. J., E. Davoust, and M. Minekus. 2004. Adaptive function of soil consumption: an in vitro study modeling the human stomach and small intestine. Journal of Experimental Biology 207: 319-324.

El-Masry, K. A., and A. S. Nasr. 1996. The role of folic acid and iron in reproductive performance of the New Zealand white does and their kits. World Rabbit Science 4: 127131.

Expert Committee on Soil Survey. 1983. The Canada Soil Information System: Manual for Describing Soils in the Field. Research Branch, Agriculture Canada, Ottawa, Ontario. 175 pages.

Faber, W. E., A. Pehrson, and P. A. Jordan. 1993. Seasonal use of salt blocks by mountain hares in Sweden. Journal of Wildlife Management 57: 842-846.

Fraser, D., and E. Reardon. 1980. Attraction of wild ungulates to mineral-rich springs in central Canada. Holarctic Ecology 3: 36-40.

Gotelli, N. J., and A. M. Ellison. 2004. A primer of ecological statistics. Sinauer Associates, Inc. Publishers, Sunderland, Massachusetts. 510 pages.

Hodges, K. E., and A. R. E. Sinclair. 2003. Does predation risk cause snowshoe hares to modify their diets? Canadian Journal of Zoology 81: 1973-1985.

Hodges, K. E., R. Boonstra, and C. Krebs. 2006. Overwinter mass loss of snowshoe hares in the Yukon: starvation, stress, adaptation or artefact? Journal of Animal Ecology 75 : 1-13.

Houston, D. C., J. D. Gilardi, and A. J. Hall. 2001. Soil consumption by elephants may help to minimize the toxic effects of plant secondary compounds in forest browse. Mammal Review 31: 249-254.

Krishnamani, R., and W. C. Mahaney. 2000. Geophagy among primates: adaptive significance and ecological consequences. Animal Behaviour 59: 899-915.

Mahaney, W. C., and R. Krishnamani. 2003. Understanding geophagy in animals: standard procedures for sampling soils. Journal of Chemical Ecology 29: 1503-1524.

Mahaney, W. C., M. W. Milner, K. Sanmugadas, R. G. V. Hancock, S. Aufreiter, R. Wrangham, and H. W. Pier.
1997. Analysis of geophagy soils in Kibale Forest, Uganda. Primates 38: 159-176.

Mahaney, W. C., M. W. Milner, H. Mulyono, R. G. V. Hancock, S. Aufreiter, M. Reich, and M. Wink. 2000. Mineral and chemical analyses of soils eaten by humans in Indonesia. International Journal of Environmental Health Research 10: 93-109.

Meidinger, D., J. Pojar, and W. L. Harper. 1991. Chapter 14: Sub-Boreal Spruce Zone by D. Meidinger, J. Pojar, and W. L. Harper. Pages 209-221 in Ecosystems of British Columbia. Compiled and edited by D. Meidinger and J. Pojar. Special Report series no. 6. Research Branch, British Columbia Ministry of Forests, Victoria, British Columbia.

Murray, D. L. 2003. Snowshoe Hare and other hares. Pages 147-175 in Wild Mammals of North America: Biology, Management, and Conservation. Edited by G. Feldhammer, B. Thompson, and J. A. Chapman. Second edition. Johns Hopkins University Press, Baltimore, Maryland.

Murray, D. L., L. B. Keith, and J. R. Cary. 1998. Do parasitism and nutritional status interact to affect production in snowshoe hares? Ecology 79: 1209-1222.

Olsen, A., J. Nawiri, and H. Friis. 2000. The impact of iron supplementation on reinfection with intestinal helminths and Schistosoma mansoni in western Kenya. Transactions of the Royal Society of Tropical Medicine and Hygiene 94: 493-499.

Potvin, F., L. Breton, and R. Courtois. 2005. Response of beaver, moose and snowshoe hare to clear-cutting in a Quebec boreal forest: a reassessment 10 years after cut. Canadian Journal of Forest Research 35: 151-160.

Statsoft. 2009. Statistica for Windows, Version 9.0.

Tankersley, N. G., and W. C. Gasaway. 1983. Mineral lick use by moose in Alaska. Canadian Journal of Zoology 61: 2242-2249.

Vaughn, M. R., and L. B. Keith. 1981. Demographic response of experimental snowshoe hare populations to overwinter food shortage. Journal of Wildlife Management 45: 354-380

Voigt, C. C. D., K. N. Dechmann, J. Bender, B. J. Rinehart, R. H. Michener, and T. H. Kunz. 2007. Mineral licks attract neotropical seed-dispersing bats. Research Letters in Ecology 2007: Article ID 34212. 4 pages. doi:10.1155/ 2007/34212.

Wilson, M. J. 2003. Clay mineralogical and related characteristics of geophagic materials. Journal of Chemical Ecology 29: 1525-1547.

Received 13 August 2012

Accepted 8 April 2013 